\title{
RESEARCH
}

Open Access

\section{Nuclear factor kappa B activation appears weaker in schizophrenia patients with high brain cytokines than in non-schizophrenic controls with high brain cytokines}

Caitlin E. Murphy ${ }^{1,2}$ (D) Adam J. Lawther ${ }^{1}$, Maree J. Webster ${ }^{3}$, Makoto Asai ${ }^{4}$, Yuji Kondo ${ }^{4}$, Mitsuyuki Matsumoto ${ }^{4}$, Adam K. Walker ${ }^{1,2,5+}$ and Cynthia Shannon Weickert ${ }^{1,2,6^{*}+}$

\begin{abstract}
Background: High inflammation status despite an absence of known infection characterizes a subpopulation of people with schizophrenia who suffer from more severe cognitive deficits, less cortical grey matter, and worse neuropathology. Transcripts encoding factors upstream of nuclear factor kappa B (NF-kB), a major transcriptional activator for the synthesis of pro-inflammatory cytokines, are increased in the frontal cortex in schizophrenia compared to controls. However, the extent to which these changes are disease-specific, restricted to those with schizophrenia and high-neuroinflammatory status, or caused by loss of a key NF-kB inhibitor (HIVEP2) found in schizophrenia brain, has not been tested.
\end{abstract}

Methods: Post-mortem prefrontal cortex samples were assessed in 141 human brains (69 controls and 72 schizophrenia) and 13 brains of wild-type mice and mice lacking HIVEP2 (6 wild-type, 7 knockout mice). Gene expression of pro-inflammatory cytokines and acute phase protein SERPINA3 was used to categorize high and low neuroinflammation biotype groups in human samples via cluster analysis. Expression of 18 canonical and noncanonical NF-kB pathway genes was assessed by qPCR in human and mouse tissue.

Results: In humans, we found non-canonical upstream activators of NF-KB were generally elevated in individuals with neuroinflammation regardless of diagnosis, supporting NF-KB activation in both controls and people with schizophrenia when cytokine mRNAs are high. However, high neuroinflammation schizophrenia patients had weaker (or absent) transcriptional increases of several canonical upstream activators of NF-kB as compared to the high neuroinflammation controls. HIVEP2 mRNA reduction was specific to patients with schizophrenia who also had high neuroinflammatory status, and we also found decreases in NF-KB transcripts typically induced by activated microglia in mice lacking HIVEP2.

(Continued on next page)

\footnotetext{
* Correspondence: c.weickert@neura.edu.au

${ }^{+}$AKW and CSW share senior authorship

'Schizophrenia Research Laboratory, Neuroscience Research Australia, Barker

Street, Randwick, Sydney, NSW 2031, Australia

${ }^{2} \mathrm{~S} c h \mathrm{ol}$ of Psychiatry, Faculty of Medicine, University of New South Wales,

Sydney, NSW, Australia

Full list of author information is available at the end of the article
}

(c) The Author(s). 2020 Open Access This article is licensed under a Creative Commons Attribution 4.0 International License, which permits use, sharing, adaptation, distribution and reproduction in any medium or format, as long as you give appropriate credit to the original author(s) and the source, provide a link to the Creative Commons licence, and indicate if changes were made. The images or other third party material in this article are included in the article's Creative Commons licence, unless indicated otherwise in a credit line to the material. If material is not included in the article's Creative Commons licence and your intended use is not permitted by statutory regulation or exceeds the permitted use, you will need to obtain permission directly from the copyright holder. To view a copy of this licence, visit http://creativecommons.org/licenses/by/4.0/. The Creative Commons Public Domain Dedication waiver (http://creativecommons.org/publicdomain/zero/1.0/) applies to the data made available in this article, unless otherwise stated in a credit line to the data. 
(Continued from previous page)

Conclusions: Collectively, our results show that high cortical expression of pro-inflammatory cytokines and low cortical expression of HIVEP2 in a subset of people with schizophrenia is associated with a relatively weak NF-KB transcriptional signature compared to non-schizophrenic controls with high cytokine expression. We speculate that this comparatively milder NF-KB induction may reflect schizophrenia-specific suppression possibly related to HIVEP2 deficiency in the cortex.

Keywords: Schizophrenia NF-KB inflammation cortex HIVEP2 Schnurri-2

\section{Introduction}

The transcription factor nuclear factor kappa B (NF-kB) is a critical regulator of immune responses and controls the expression of various pro-inflammatory cytokines and acute phase proteins $[1,2]$ that are increased in the brain in people with schizophrenia [3-9]. Patients with elevated expression of these immune factors suffer from more severe symptoms [10-12], and fluctuations in the inflammatory milieu correlate with changes in symptom severity [13]. Thus, it is important to understand what factors are driving these inflammatory changes in people with schizophrenia. Recently, dysregulation of factors immediately upstream of $\mathrm{NF}-\mathrm{\kappa B}$ expression has been identified in the prefrontal cortex (PFC) of people with schizophrenia [14, 15]. Gene expression of members of 3 key processes are reportedly elevated in schizophrenia

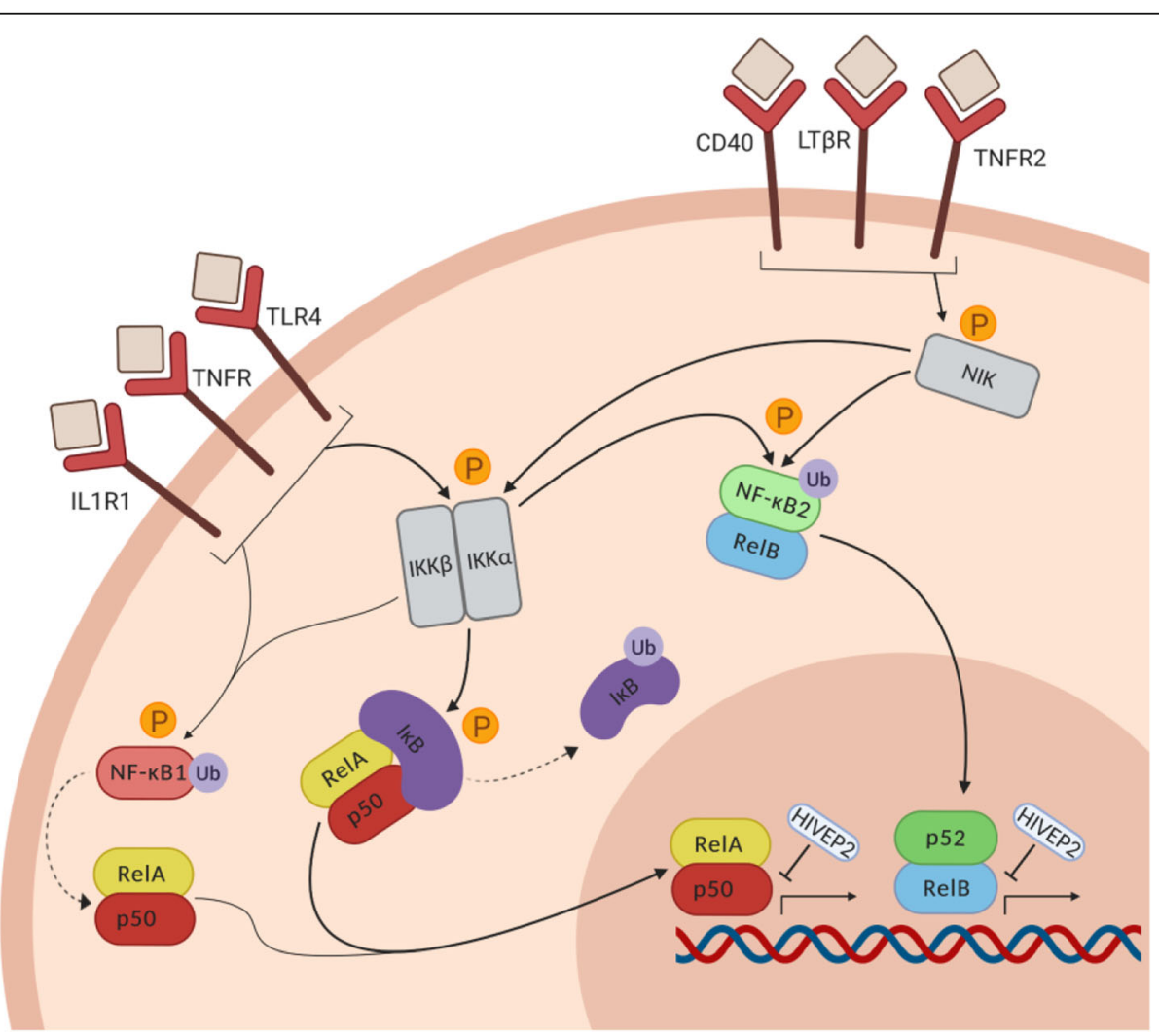

Fig. 1 The NF-kB activation pathway. Receptors of the canonical arm of the pathway include IL1R1, TNFR, and TLR4. Activation of these receptors leads to the phosphorylation of both IKK and NF-KB1. The activated IKK complex tags IKB for proteasomal degradation, unmasking the nuclear localization sequence on RelA and allowing for nuclear localisation of the p50-RelA heterodimer. Activated IKK $\beta$ also phosphorylates NF-kB1, which is partially processed by the proteasome into mature subunit p50. p50 most commonly dimerizes with RelA, and the dimer either translocates to the nucleus or binds IKB and remains in the cytoplasm. Receptors of the non-canonical arm of the pathway include CD40, LT $\beta R$, and TNFR2. Activation of these receptors leads to the phosphorylation of NIK, which activates IKKa. Both NIK and IKKa are required for the phosphorylation of NF-KB2, which acts as an inhibitor while bound to RelB in the cytoplasm. Once tagged by NIK/KKa, NF-KB2 undergoes partial processing by the proteasome into mature subunit p52. p52-RelB dimers then translocate to the nucleus. Rel-containing NF-kB dimers in the nucleus bind target gene DNA in a dimer- and cell type-specific manner to initiate transcription. HIVEP2 is a zinc finger protein that blocks NF-kBinduced gene transcription by binding $\mathrm{KB}$ sites on DNA 
compared to controls: (1) receptors that initiate NF- $\mathrm{kB}$ signalling (interleukin-1 receptor type 1 (IL1R1), tumor necrosis factor receptor superfamily member $1 \mathrm{~A}$ (TNFR1), toll-like receptor 4 (TLR4), cluster of differentiation 40 (CD40), lymphotoxin receptor beta (LT $\beta R$ ), and TNFR superfamily member 1B (TNFR2)); (2) subunits that form NF- $\mathrm{kB}$ dimers (proto-oncogene RelA (RelA), proto-oncogene c-Rel (cRel), NF-kB subunit 1 (NFKB1), and NF-kB subunit 2 (NFKB2)); and (3) kinases that induce their translocation into the nucleus (inhibitor of NF- $\mathrm{kB}$ kinase subunit alpha (IKK $\alpha)$, IKK beta (IKK $\beta)$, and NF-kB-inducing kinase (NIK)). Volk et al. also found increased expression of NF- $\kappa B$ inhibitor alpha $(\mathrm{I} \kappa \mathrm{B} \alpha)$, which is upregulated by NF- $\mathrm{kB}$ activation itself in a negative feedback mechanism [16]. In contrast, another NF- $\mathrm{kB}$ inhibitor, human immunodeficiency virus type 1 enhancer binding protein 2 (HIVEP2) is decreased in schizophrenia cortex compared to controls [14]. These findings suggest that NF- $\mathrm{kB}$ is overactive in the cortex in people with schizophrenia and drives neuroinflammation in patients that may be causally relevant to their symptomatology.

The NF- $\mathrm{KB}$ activation pathway consists of two armsthe canonical and non-canonical arms-that are induced by different receptors and involve different intracellular signalling proteins (Fig. 1). Both arms of the pathway require stimulus-induced activation of NF-kB-inducing kinases (NIK and IKKs) that tag NF-KB inhibitors for degradation ( $\mathrm{I} \kappa \mathrm{B}, \mathrm{NF}-\mathrm{k} \mathrm{B} 1$ ) or processing into mature subunits (NF-kB1/p50 and NF-kB2/p52). After this step, transcriptionally active $\mathrm{NF}-\mathrm{\kappa B}$ dimers translocate into the nucleus and bind $\mathrm{\kappa B}$ sites on target DNA of cytokines to initiate gene transcription. Though there is a degree of overlap in target genes, $\mathrm{\kappa} B$ binding preferences of dimers differ between the canonical and noncanonical arms ([17]; see Fig. 1). Additionally, the two arms have distinct functions in different cell types [1, 18]. Recent studies suggest overactivity of both arms of the NF- $\mathrm{kB}$ activation pathway in the cortex of people with schizophrenia [14, 15], but how this may differ from NF-kB activation in the normal human brain when inflamed has not been addressed.

Since degree of inflammation in schizophrenia relates to disease stage and symptom level $[11,12,19,20]$, it is likely that changes in cortical NF- $\mathrm{kB}$ activity occur only during active neuroinflammation and normalize (at least partially) during periods of symptom remission [12]. Thus, in the context of chronic schizophrenia, the subset of patients with neuroinflammation $[3-6,9,11]$ plausibly drives the observed diagnostic effects in NF- $\mathrm{kB}$ gene expression. Furthermore, we hypothesize that the nature of neuroinflammation in schizophrenia may differ from that which occurs in non-schizophrenic controls who also have signs of neuroinflammation. Previous studies have only compared people with schizophrenia (who are more likely than people without schizophrenia to have inflammation) [3, 4] to non-schizophrenic controls; thus, it is possible that the differences observed are actually related to two underlying variables: diagnosis and neuroinflammatory status. Untangling these effects requires first identifying those cases that are in an active state of neuroinflammation based on increases in proinflammatory cytokines. Since previous studies have not considered the neuroinflammatory state of individuals, the extent to which changes in NF- $\kappa$ B-related transcripts are associated with inflammation or are specific to schizophrenia has not been explored. We sought to tease out which of these changes may be specific to, blunted or exaggerated in schizophrenia, and which may be related more generally to the neuroinflammatory state.

The driving factors behind cortical NF- $\mathrm{kB}$ dysregulation in schizophrenia are not known, and adult mice subjected to maternal immune activation in utero do not recapitulate changes in NF- $\mathrm{kB}$-related transcripts [15]. HIVEP2, a protein that regulates NF- $\mathrm{kB}$ activity in the brain by preventing its target DNA-binding ([21, 22]; Fig. 1), is downregulated in the dorsolateral PFC of people with schizophrenia and cortical inflammation $[14,23]$. HIVEP2 deletion in mice leads to several schizophrenia-like behavioral and neuropathological phenotypes [24] and allows us to test which NF-kBrelated transcripts may be downstream of blunted HIVE P2 expression in schizophrenia or in controls. We measured the same 18 NF-kB-related messenger RNAs (mRNAs) in the cortex of mice lacking Schnurri-2 (Shn2; murine HIVEP2) and wild-type controls to determine the extent to which HIVEP2 deletion recapitulates schizophrenia-associated or neuroinflammationassociated NF-kB dysregulation within the mammalian brain. The primary aims of this study were to determine if inflammation-associated changes in upstream regulators of cortical NF-kB are different in people with schizophrenia than in non-schizophrenic controls, and to test the extent to which disease-associated changes in upstream regulators of cortical NF- $\mathrm{KB}$ would be consistent with those caused by a reduction in HIVEP2.

\section{Methods}

\section{Human post-mortem brain tissue samples}

Post-mortem dorsolateral PFC (Brodmann area 46) tissue was obtained from the New South Wales Tissue Resource Centre (TRC; 37 individuals with schizophrenia and 37 controls) and the Stanley Medical Research Institute (SMRI; 35 individuals with schizophrenia and 32 controls) (full demographics Supplementary Table 1). Details of brain collection and storage and determination of clinical and tissue factors for this cohort have been reported $[4,25]$. Individuals were predetermined as having 
a low- or high-neuroinflammatory status or biotype based on expression levels of pro-inflammatory mRNAs as described in Fillman et al. [3] and Fillman et al. [4]. Briefly, the existence of inflammatory subgroups was tested in separate cohorts using a recursive two-step cluster analysis. The overall model quality was required to be $>0.5$ (TRC) or $>0.4$ (SMRI), with predictors removed if they did not contribute $>0.5$ (TRC) or $>0.25$ (SMRI) to the model on a scale of $0-1.0$. Serpin Family A Member 3 (SERPINA3), IL-6, IL-8, and IL-1 $\beta$ transcripts were significant contributors to the model in both cohorts [3, 4]. TNF and IL1RL1 transcripts as well as brain $\mathrm{pH}$ also contributed to the formation of clusters in the SMRI cohort [4]. After combining cohorts, final group numbers were 57 low neuroinflammation controls, 12 high neuroinflammation controls, 42 low neuroinflammation schizophrenia, and 30 high neuroinflammation schizophrenia).

\section{RNA extraction, complementary DNA (cDNA) synthesis, and quantitative real-time PCR}

For both cohorts, total RNA was extracted from the TRC dorsolateral PFC tissue using the Trizol method (Invitrogen, Carlsbad, CA, USA) per manufacturer protocol (Life Technologies). RNA quality and concentration were assessed on the Agilent Technologies 2100 Bioanalyzer and Nanodrop ND-1000 spectrophotometer. Complimentary DNA was synthesized from $1 \mu \mathrm{g}$ total RNA per case using SuperScript ${ }^{\circ}$ First-Strand Synthesis Kit IV and random hexamers following manufacturer instructions (Life Technologies). The mRNA expression of 18 NF-KB pathway genes was measured by reverse transcriptase-quantitative PCR (qPCR) in Fluidigm ${ }^{\circ}$ BioMark $^{\text {Tix }}$ HD system (South San Francisco, CA, USA) at the Ramaciotti Centre for Genomics (Kensington, NSW, Australia) using pre-designed Taqman Gene Expression Assays: IL1R1 (Hs00991010_m1), TNFR1 (Hs01042313_ m1), TLR4 (Hs00152939_m1), CD40 (Hs00374176_m1), LTßR (Hs01101194_m1), TNFR2 (Hs00961750_m1), IKK $\alpha$ (Hs00989497_m1), IKK $\beta$ (Hs01559460_m1), NIK (Hs01089753_m1), І ІкB $\alpha$ (Hs00153283_m1), ІкB $\beta$ (Hs00182115_m1), IкBE (Hs00234431_m1), RelA (Hs01042014_m1), cRel (Hs00968440_m1), RelB (Hs00232399_m1), NFKB1 (Hs00765730_m1), NFKB2 (Hs00174517_m1), and HIVEP2 (Hs00198801_m1). No reverse transcriptase controls and no template controls were included to rule out genomic DNA contamination and reagent contamination, respectively. Normalized relative quantities $(2-\Delta \Delta \mathrm{Ct})$ of each mRNA were calculated using the geometric mean of three housekeeper genes that did not differ between diagnostic groups in either cohort (glyceraldehyde 3-phosphate dehydrogenase, Hs99999905_m1; TATA-binding protein, Hs00427620_m1; ubiquitin C, Hs00824723_m1).

\section{Schnurri-2 knockout mice}

Seven Shn2 knockout (KO) mice and six wild-type control littermates were obtained by breeding heterozygotes with a C57BL/6J background and those with a BALB/cA background. Animals were group-housed under a 12-h light/dark cycle at a constant room temperature $(23 \pm 2$ ${ }^{\circ} \mathrm{C}$ ) and humidity (55 $\left.\pm 15 \%\right)$, with free access to standard laboratory chow and water. At 17 weeks, mice were sacrificed via cervical dislocation and decapitation under isoflurane anesthesia. Whole brains were removed, and medial prefrontal cortex and infralimbic cortex samples were punched-out and snap frozen for RNA extraction and cDNA preparation (using total $1.5 \mu \mathrm{g}$ RNA per mouse sample) as described above. The following probes were used for qPCR: IL1R1 (Mm00434237_m1), TNFR (Mm01182929_m1), TLR4 (Mm00445273_m1), CD40 (Mm00441891_m1), LTßR (Mm00440235_m1), TNFR2 (Mm00441889_m1), IKKa (Mm00432529_m1), IKK $\beta$ (Mm01222247_m1), NIK (Mm00444166_m1), ІкB $\alpha$

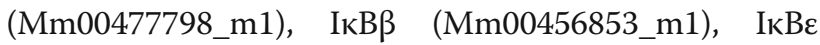
(Mm01269649_m1), RelA (Mm00501346_m1), cRel (Mm01239661_m1), RelB (Mm00485664_m1), NFKB1 (Mm00476361_m1), and NFKB2 (Mm00479807_m1). No reverse transcriptase controls and no template controls were included to rule out genomic DNA contamination and reagent contamination, respectively. Normalized relative quantities $(2-\Delta \Delta \mathrm{Ct})$ of each mRNA were calculated using the geometric mean of two housekeeper genes (TBP, Hs99999905_m1; UBC, Hs00824723_m1).

\section{Statistical analyses}

Independent samples $t$ tests or independent samples Mann-Whitney $U$ tests were used to confirm no differences in age at death, RIN, or PMI between controls and patients (Table 1) or between high and low inflammation biotypes (Table 2). Normalized relative mRNA quantities $>2$ standard deviations from the group mean (low neuroinflammation control, high neuroinflammation control, low neuroinflammation schizophrenia, high neuroinflammation schizophrenia; wild-type mice, Shn2 $\mathrm{KO}$ mice) were considered outliers and excluded from analyses (average 3 low neuroinflammation control, 1 high neuroinflammation control, 2 low neuroinflammation schizophrenia, and 1 high neuroinflammation schizophrenia cases). mRNAs that were not normally distributed were log-transformed, square roottransformed, or inverted to achieve normality. The distribution of IкB $\beta$ mRNA did not normalize, so nonnormal untransformed data was analyzed. Correlations were performed to assess the relationship between each mRNA and age at death, RNA integrity number (RIN), $\mathrm{pH}$, and postmortem interval (PMI). If correlations were significant, the variable(s) was included as a covariate in 
Table 1 Comparison of demographic variables between diagnostic groups

\begin{tabular}{|c|c|c|c|c|}
\hline & Control $(\mathrm{N}=69)$ & Schizophrenia $(\mathrm{N}=72)$ & & \\
\hline & Mean (SD) & Mean (SD) & $t / U / x^{2}(d f)$ & p-value \\
\hline Age & $48.01(12.17)$ & $47.07(12.45)$ & $t(139)=0.46$ & 0.65 \\
\hline $\operatorname{Sex}(m / f)$ & $53 / 16$ & $50 / 22$ & $x^{2}(1)=0.97$ & 0.32 \\
\hline RIN & $7.73(0.78)$ & $7.86(0.83)$ & $t(139)=-0.92$ & 0.36 \\
\hline PMI (hrs) & $27.15(12.31)$ & $29.89(14.63)$ & $U=2743.00$ & 0.26 \\
\hline $\mathrm{pH}$ & $6.63(0.28)$ & $6.55(0.28)$ & $U=1988.50$ & $<0.05$ \\
\hline
\end{tabular}

subsequent analyses, excluding $\mathrm{pH}$ [26]. For schizophrenia samples, correlations were performed with each mRNA and calculated lifetime chlorpromazine equivalent to assess the relationship between expression of each transcript and anti-psychotic exposure. Two-way ANOVAs (diagnosis, inflammation, diagnosis $\times$ inflammation) were used to assess main effects of diagnosis and neuroinflammatory state and/or their interaction effect on expression of each gene. Planned post hoc $t$ tests were used to compare gene expression between (1) low neuroinflammation controls and high neuroinflammation controls, (2) low neuroinflammation schizophrenia and high neuroinflammation schizophrenia, and (3) high neuroinflammation schizophrenia and high neuroinflammation controls. For mouse data, mean substitution for outliers ( $n=1$ for IкB $\alpha, n=1$ for TLR4, replacement with the group mean) was used to preserve statistical power. Independent samples $t$ tests were used to examine differences in expression of the NF- $\mathrm{kB}$-related mRNAs between Shn2 KO and wild-type mice.

\section{Results}

Membrane-bound NF-кB-activating receptor mRNAs are increased in inflammation

First, we detected viable expression levels of all $18 \mathrm{NF}$ $\kappa \mathrm{B}$-pathway members in human brain. We found a main effect of inflammation status for all six receptor mRNAs measured (IL1R1, TLR4, TNFR, TNFR2, LT $\beta R$, CD40; all $F>27.028$, all $p<0.0001$; Fig. 2). For TLR4, an interaction effect of diagnosis $\times$ inflammation was apparent such that the increase in mRNA related to high neuroinflammatory status was only evident in controls $(F(1,131)$ $=11.995, p=0.001)$. Compared to non-schizophrenic

Table 2 Comparison of demographic variables between neuroinflammatory biotypes

\begin{tabular}{lllll}
\hline & High $(\mathrm{N}=42)$ & Low $(\mathrm{N}=99)$ & & \\
& Mean (SD) & Mean (SD) & $\mathrm{t} / \mathrm{U} / \mathrm{X}^{2}(\mathrm{df})$ & p-value \\
\hline Age & $47.33(12.14)$ & $47.62(12.40)$ & $\mathrm{t}(139)=0.13$ & 0.90 \\
Sex (m/f) & $31 / 11$ & $72 / 27$ & $\mathrm{X}^{2}(1)=0.02$ & 0.90 \\
RIN & $7.80(0.83)$ & $7.80(0.80)$ & $\mathrm{t}(139)=-0.01$ & 0.99 \\
PMI (hrs) & $27.52(16.60)$ & $28.98(12.12)$ & $\mathrm{U}=1852.00$ & 0.31 \\
$\mathrm{pH}$ & $6.37(0.28)$ & $6.68(0.23)$ & $\mathrm{U}=825.50$ & $<0.01$ \\
\hline
\end{tabular}

controls with neuroinflammation, patients with neuroinflammation had $35 \%$ less TLR4 mRNA $(t(38)=3.031, p$ $=0.004)$. In contrast, TNFR mRNA was upregulated in patients compared to controls overall (main effect of diagnosis $F(1,130)=4.061, p=0.046,+44 \%)$. We found no main effect of diagnosis on expression of IL1R1, TNFR2, LT $\beta R$ or CD40 (all $F<1.559$, all $p>0.214$; Fig. $2)$. However, when we excluded the small number of high neuroinflammation controls $(n=12)$ from analysis, all six receptor mRNAs were increased diagnostically in schizophrenia compared to controls (all $p<0.006$ ), consistent with previous findings.

\section{NF-kB-inducing kinase mRNAs are differentially upregulated in inflamed controls and inflamed patients} Stimulus-dependent activation of NF-kB-inducing kinases occurs downstream of receptor-ligand binding and is necessary for signal propagation. In the canonical pathway, IKK $\alpha$ and IKK $\beta$ tag IKBs for degradation, which is essential for the translocation of NF- $\mathrm{kB}$ dimers into the nucleus to bind target DNA. We found a main effect of inflammation on IKK $\alpha$ and IKK $\beta$ transcripts (IKK $\alpha$ $F(1,131)=7.817, p=0.006$; $\operatorname{IKK} \beta F(1,133)=12.666, p=$ 0.001 ; Fig. 3), which were upregulated in high vs. low neuroinflammation groups. However, post hoc $t$ tests revealed that this effect was only evident in controls (IKK $\alpha$ $t(65)=4.345, p<0.0001 ; \operatorname{IKK} \beta t(65)=4.299, p<$ 0.0001 ), and that high neuroinflammation patients had $28 \%$ and $30 \%$ lower expression of IKK $\alpha$ and IKK $\beta$ than high neuroinflammation controls, respectively (IKK $\alpha$ $t(38)=4.00, p<0.001 ; \operatorname{IKK} \beta t(40)=2.74, p<0.01)$. We found a main effect of diagnosis on IKK $\alpha$ mRNA, in that levels were decreased in schizophrenia compared to controls $(F(1,131)=15.449, p<0.0001)$, but when high neuroinflammation controls were excluded, there was no difference in expression diagnostically $(t(121)=-1.234$, $p=0.220$ ). For IKK $\beta$, we were unable to detect a main effect of diagnosis with or without the inclusion of high neuroinflammation controls (all $p>0.147$ ). The noncanonical pathway requires activation of NF- $\mathrm{kB}$-inducing kinase NIK, which we found was increased in high neuroinflammation relative to low neuroinflammation individuals in both controls and patients (main effect of inflammation $F(1,131)=20.043, p<0.0001$; Fig. 3). We 

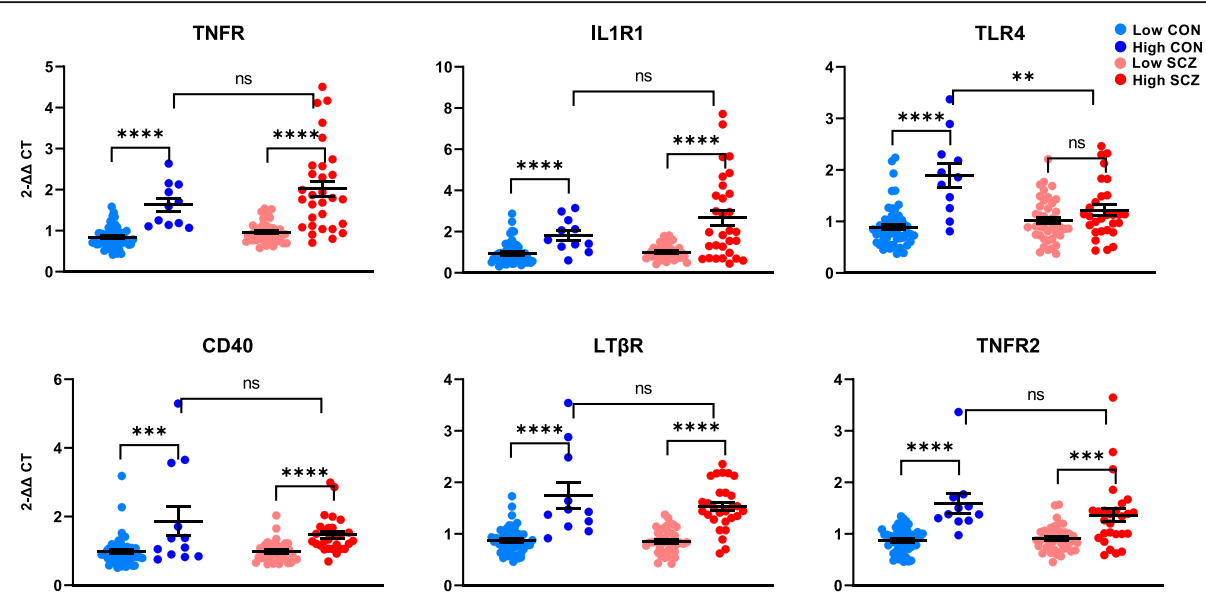

Fig. 2 Gene expression of NF-KB-activating receptors in the post-mortem dorsolateral prefrontal cortex of controls (CON) and people with schizophrenia (SCZ). Diagnostic groups were stratified based on neuroinflammatory biotype at time of death (low neuroinflammation or high neuroinflammation). High neuroinflammation groups had higher expression of all receptors in both diagnoses, with the exception of TLR4 mRNA which did not differ between high neuroinflammation and low neuroinflammation in schizophrenia, and was decreased in patients with inflammation compared to non-schizophrenic controls with neuroinflammation. Diagnostically, TNFR mRNA was upregulated in schizophrenia compared to controls $(p=0.046)$. Error bars depict standard error of the mean. ${ }^{*} p<0.05,{ }^{* *} p<0.01,{ }^{* * *} p<0.001,{ }^{* * *} p<0.0001$, ns $=$ not significant

were unable to detect an effect of diagnosis on NIK mRNA unless high neuroinflammation controls were excluded, in which case we did find a main effect of diagnosis, where NIK mRNA was increased in schizophrenia $(t(123)=-2.652, p=0.009)$.

\section{Increased expression of canonical NF-KB inhibitor mRNAs is associated with inflammation but is blunted in schizophrenia}

I $\mathrm{B} \alpha$, I $\mathrm{K} B \beta$, and I $\mathrm{I} B \varepsilon$ remain largely in the cytoplasm bound to NF- $\mathrm{KB}$ dimers and are degraded in response to canonical IKK activation. The resynthesis of IKBs is stimulusdependent and is driven by NF- $k B$ in a negative feedback loop. As such, IkB mRNA upregulation could result from canonical or non-canonical NF- $\mathrm{kB}$ activation even though the latter occurs independently of IкB. We found a main effect of inflammation on IкB $\alpha$ and I $\mathrm{I} B \beta$ transcripts in the human PFC, where IkB $\alpha$ and I $\mathrm{I} B \beta$ were increased in high vs. low neuroinflammatory status $(\mathrm{I} \kappa \mathrm{B} \alpha F(1,127)=86.012$, $p<0.0001$, ІкB $\beta F(1,137)=11.671, p<0.0001)$ to a greater extent in controls than in schizophrenia (Fig. 4). Because of this, both mRNAs were decreased in patients overall when testing the main effect of diagnosis $(\mathrm{I} \kappa \mathrm{B} \alpha$ $F(1,127)=4.868, p=0.029 ; \operatorname{I\kappa B} \beta F(1,137)=4.585, p=$ $0.034)$. When we excluded high neuroinflammation controls, IкB $\alpha$ mRNA was, in fact, higher in schizophrenia compared to controls overall $(F(1,117)=6.054, p=0.015)$. IкBE mRNA was not associated with inflammation in either controls or patients, but was decreased in schizophrenia compared to controls overall $(F(1,133)=6.993, p=$ 0.009; Fig. 4). While we did not detect a main diagnostic difference in expression of HIVEP2, an atypical nuclear
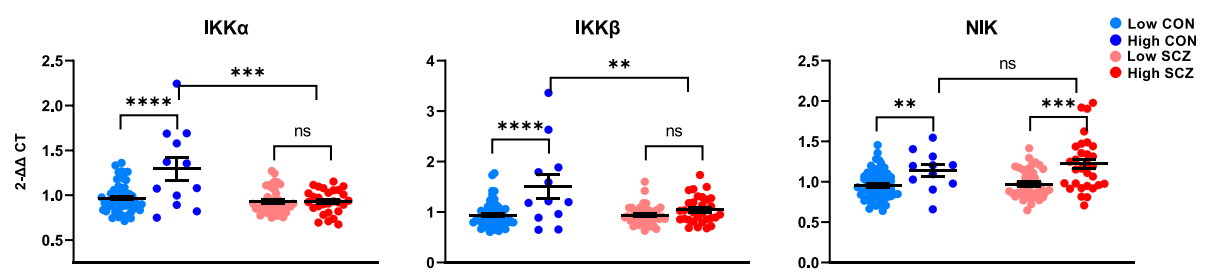

Fig. 3 Gene expression of NF-KB-inducing kinases in the postmortem dorsolateral prefrontal cortex of controls (CON) and people with schizophrenia (SCZ). Diagnostic groups were stratified based on neuroinflammatory biotype at time of death (low neuroinflammation or high neuroinflammation). In controls, all three kinase transcripts (IKKa, IKKß, NIK) were elevated in people with high neuroinflammation. In schizophrenia, only NIK was elevated in people with high neuroinflammation; expression of IKKa and IKK $\beta$ did not differ between neuroinflammatory biotypes. Diagnostically, IKKa mRNA was downregulated in schizophrenia compared to controls $(p<0.0001)$. Error bars depict standard error of the mean. ${ }^{* *} p<0.01,{ }^{* * *} p<0.001,{ }^{* * *} p<0.0001$, ns $=$ not significant 

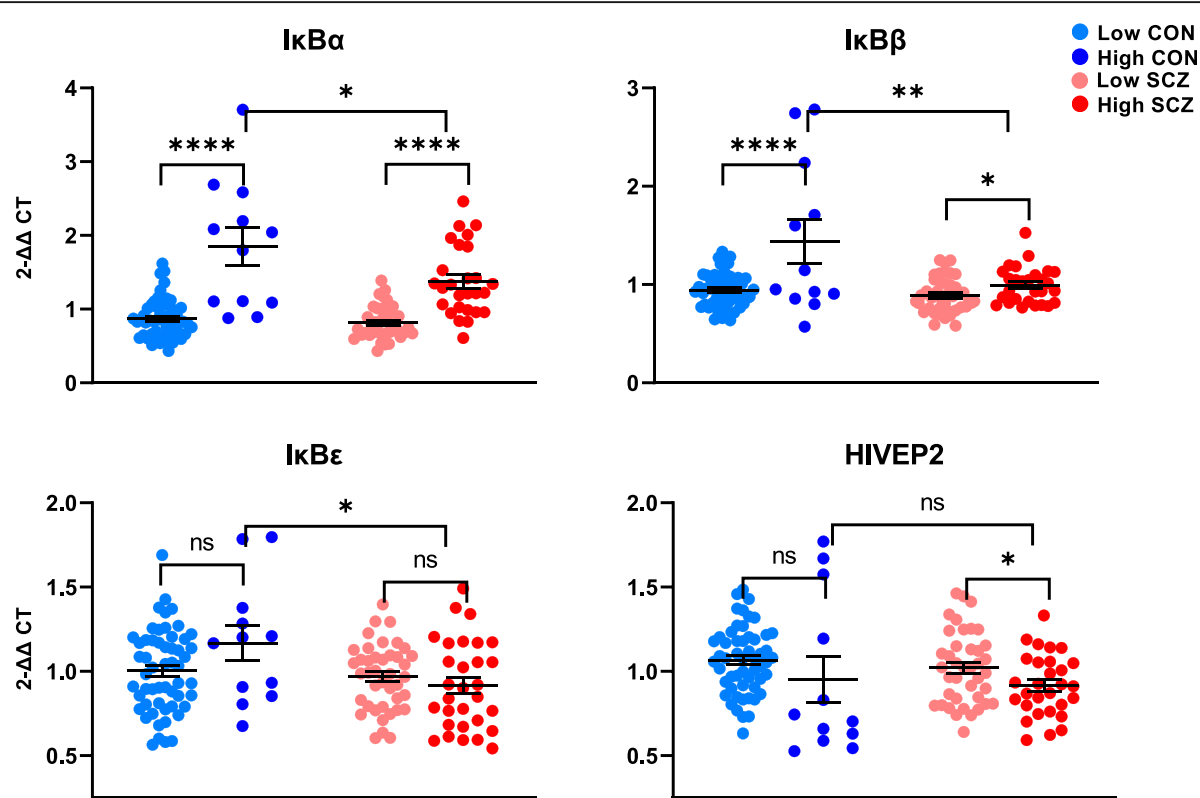

Fig. 4 Gene expression of NF-KB inhibitors in the post-mortem dorsolateral prefrontal cortex of controls (CON) and people with schizophrenia (SCZ). Diagnostic groups were stratified based on neuroinflammatory biotype at time of death (low neuroinflammation or high neuroinflammation). Expression of $\mathrm{I} B \mathrm{Ba}$ and $\mathrm{IKB} \beta$ was increased in high neuroinflammation groups compared to low neuroinflammation groups. However, both transcripts were higher in non-schizophrenic controls with neuroinflammation than in patients with neuroinflammation. Neuroinflammatory biotype was not associated with IKBE mRNA; however, high neuroinflammation controls had higher expression of I $\mathrm{kB} \varepsilon$ than high neuroinflammation patients. All three traditional NF-KB inhibitors were decreased overall in schizophrenia compared to controls (all $p<$ 0.034). HIVEP2 mRNA was associated with neuroinflammation in patients but not in controls and did not differ diagnostically. Error bars depict standard error of the mean. ${ }^{*} p<0.05,{ }^{* *} p<0.01,{ }^{* * *} p<0.0001$, ns $=$ not significant

inhibitor of NF-kB, between schizophrenia and controls overall $(F(1,130)=0.001, p=0.977)$, we saw an effect of inflammation within schizophrenia $(t(67)=2.151, p=$
0.035; Fig. 4) where HIVEP2 was decreased in high neuroinflammation schizophrenia compared to low neuroinflammation schizophrenia. When omitting high
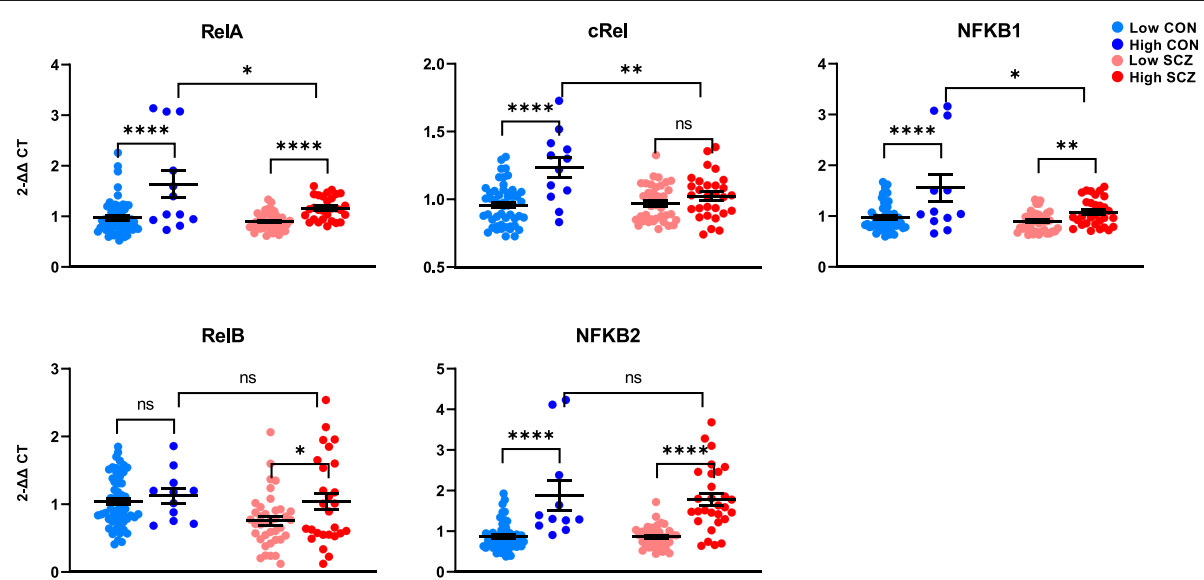

Fig. 5 Gene expression of NF-KB subunits and subunit precursors in the post-mortem dorsolateral prefrontal cortex of controls (CON) and people with schizophrenia (SCZ). Diagnostic groups were stratified based on neuroinflammatory biotype at time of death (low neuroinflammation or high neuroinflammation). RelA, cRel, and NFKB1 mRNAs were increased in high neuroinflammation groups in both diagnoses; however, high neuroinflammation controls had significantly higher expression of all three transcripts compared to high neuroinflammation patients. RelB expression was associated with neuroinflammation only in patients and was decreased in schizophrenia compared to controls overall ( $p=0.013)$. NFKB2 mRNA was upregulated in high neuroinflammation relative to low neuroinflammation and did not differ between non-schizophrenic controls with neuroinflammation and patients with neuroinflammation. Error bars depict standard error of the mean. ${ }^{*} p<0.05,{ }^{* *} p<0.01,{ }^{* * * *} p$ $<0.0001, \mathrm{~ns}=$ not significant 
neuroinflammation controls from analysis, HIVEP2 mRNA was decreased in schizophrenia compared to controls $(F(1,120)=7.822, p=0.006)$ as expected.

\section{NF-KB subunit-encoding transcripts involved in canonical signalling-but not those involved in non-canonical signalling-are blunted in schizophrenia}

The most abundant transcriptionally active NF- $\mathrm{kB}$ dimer is comprised of RelA bound to p50 [27], which is constitutively processed from NF- $\mathrm{kB} 1$. The processing of NF$\kappa \mathrm{B} 1$ is enhanced by NF- $\mathrm{B}$ receptor-ligand binding [28]. We found a main effect of inflammation on RelA and NFKB1 mRNA overall (RelA $F(1,133)=29.696, p<$ 0.0001; NFKB1 $F(1,133)=15.354, p<0.0001$; Fig. 5) and no main effect of diagnosis on either transcripts (RelA $p$ $=0.374$; NFKB1 $p=0.924)$. However, controls with cortical inflammation had greater expression of both RelA and NFKB1 transcripts than patients with cortical inflammation (RelA $t(39)=2.575, p=0.014,+29 \%$; NFKB1 $t(40)=2.528, p=0.016,+31 \%)$. cRel, which also binds p50 to activate canonical NF- $k B$ signalling [29], was associated with neuroinflammation via upregulation in controls but not in patients (interaction effect $F(1$, $130)=9.317, p=0.003$; Fig. 5). High neuroinflammation controls had $17 \%$ more cRel mRNA than high neuroinflammation patients $(t(39)=3.13, p=0.003)$. Consequently, the main effect of diagnosis on cRel mRNA was a decrease in schizophrenia compared to controls overall $(F(1,130)=6.483, p=0.012)$, but was not detected when high neuroinflammation controls were excluded $(F(1$, $120)=2.034, p=0.156)$. NF- $\mathrm{kB} 2$ binds RelB and is processed into p52 to form the sole transcriptionally active $\mathrm{NF}-\mathrm{kB}$ dimer of the non-canonical pathway [27]. In its unprocessed form, NF- $\mathrm{B} 2$ can also inhibit canonical NF- $\kappa B$ signalling [30]. We found a main effect of inflammation on NFKB2 mRNA, where high neuroinflammatory status was associated with elevated expression regardless of diagnosis $(F(1,127)=71.314, p<0.0001$; Fig. 5), and found no difference in expression NFKB2 levels between controls with cortical inflammation and patients with cortical inflammation. We did not detect a main effect of diagnosis on NFKB2 expression overall $(F(1,127)=0.009, p=0.924)$. However, when we excluded high neuroinflammation controls, NFKB2 mRNA was upregulated in schizophrenia diagnostically $(F(1$, $118)=13.601, p<0.0001)$. For RelB transcript, we found a main effect of diagnosis, where people with schizophrenia had decreased RelB mRNA overall, with $(F(1$, $127)=6.306, p=0.013,-17 \%)$ or without $(t(118)=$ $2.496, p=0.014,-16 \%)$ the inclusion of high neuroinflammation controls (Fig. 5). Post hoc $t$ tests also revealed that RelB was not changed in high neuroinflammation controls compared to low neuroinflammation controls; however, high neuroinflammation patients had greater RelB expression than low neuroinflammation patients $(t(63)=2.178, p=0.033$; Fig. 5$)$.

Expression of NF-kB-related mRNAs is related to brain $\mathrm{pH}$ As expected, people with schizophrenia had significantly lower brain $\mathrm{pH}$ than controls (Table 1 [26]) and high neuroinflammation samples had significantly lower brain $\mathrm{pH}$ than low neuroinflammation samples (Table 2). Since higher inflammatory signaling is related to lower tissue $\mathrm{pH}$ in both controls and patients, almost all of the 18 NF-kB-related mRNAs were negatively correlated with brain $\mathrm{pH}$ (Supplementary Table 2). Thus, covarying for $\mathrm{pH}$ would also remove some of the impact of diagnosis or inflammation status, and was not considered necessary as the groups were matched for RINs. People with schizophrenia were also significantly more likely than controls to be smokers at their time of death (Supplementary Table 1); however, 16 of 18 mRNAs measured did not differ between smokers and nonsmokers (all $F<3.308$, all $p>0.07$ ). We did find that IL1R1 and TNFR transcripts were higher in the dorsolateral PFC of smokers (IL1R1 $F(1,110)=9.906, p=0.002$; TNFR $F(1,111)=5.376, p=0.022)$.

\section{Anti-psychotic exposure is related to expression of some NF-kB-related mRNAs}

Anti-psychotic drugs exert anti-inflammatory effects in the periphery by upregulating anti-inflammatory cytokines and reducing the expression of pro-inflammatory cytokines [31]. We ran correlations between each NF- $\kappa B$ mRNA and lifetime anti-psychotic exposure in patients to assess the relationship between anti-psychotics and NF- $\kappa B$ activation in the cortex. We found that the levels of three mRNAs TNFR, I $\mathrm{KB} \alpha$ and NFKB2 were positively correlated with lifetime anti-psychotic (chlorpromazine equivalent) exposure (Supplementary Table 2).

\section{NF-KB transcripts are altered in the frontal cortex of Schnurri-2 knockout mice}

HIVEP2 is decreased in the brain in high inflammation schizophrenia [15, 23], and HIVEP2 (Shn2) deletion induces neuroinflammation in adult mice [23, 24]. We compared the mRNA levels of factors upstream of NF$\kappa \mathrm{B}$ expression in the cortex of Shn2 KO mice to determine which of the changes seen in high neuroinflammation schizophrenia could be caused by HIVEP2 deficiency. In mice, Shn2 deletion led to substantial downregulation of NF- $\mathrm{kB}$ receptor mRNAs CD40 ($28 \% ; t(11)=2.942, p=0.013)$ and TLR4 $(-13 \% ; t(11)=$ $2.424, p=0.034$; Fig. 6). The largest effect of Shn2 deletion in the prefrontal cortex was on NIK mRNA, which was reduced by $37 \%$ in Shn2 KO mice $(t(1)=3.932, p$ $=0.002$; Fig. 6). Consistent with NF- $\mathrm{kB}$ activation, we found a trend of higher expression of $\mathrm{I} \kappa \mathrm{B} \alpha(+17 \%)$ in 


\section{Receptors}

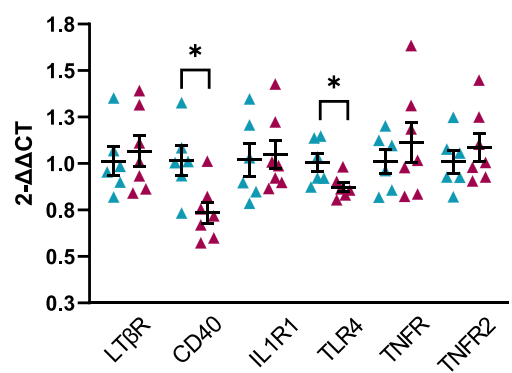

Inhibitors

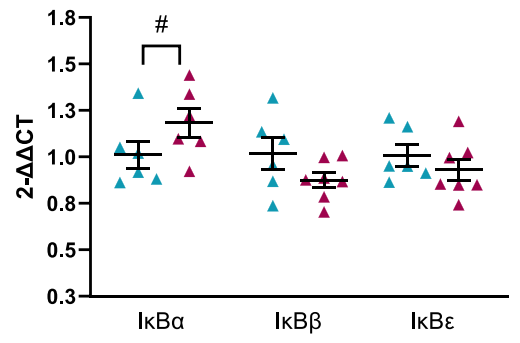

Kinases

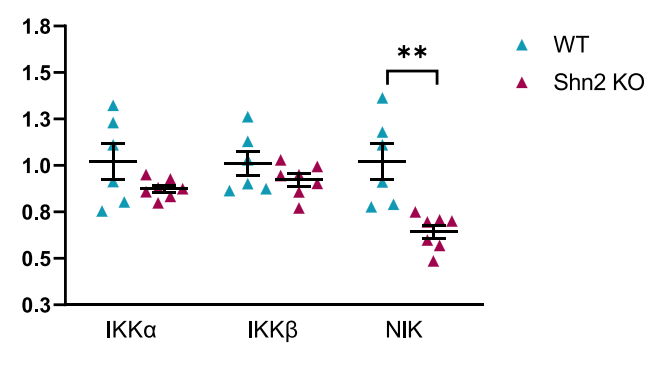

Subunits

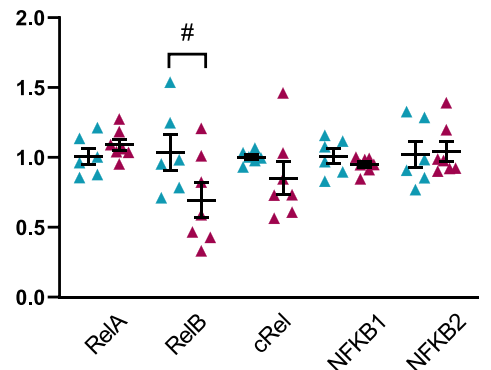

Fig. 6 Gene expression of NF-KB transcripts in the prefrontal cortex of wild-type (WT) and Schnurri-2 knockout (Shn2 KO) mice. CD40, TLR4, and NIK mRNAs were significantly downregulated in Shn2 KO mice. Error bars depict standard error of the mean. ${ }^{*} p<0.05,{ }^{* *} p<0.01, \# p=0.08$

Shn2 KO mice compared to wild-type mice $(t(11)=-$ $1.930, p=0.080)$. RelB mRNA was lower $(-33 \%)$ in Shn2 KO mice than wild-type mice but this effect also failed to reach significance $(t(1)=1.924, p=0.081)$. Expression of many NF- $\kappa B$ transcripts (IL1R1, TNFR, TNFR2, LT $\beta R$, I $\kappa \beta \beta$, I $B \varepsilon$, IKK $\alpha$, IKK $\beta$, NFKB1, NFKB2, RelA, and cRel) did not differ between wild-type and Shn2 KO mice (all $p>0.13$; Fig. 6).

\section{Discussion}

In contrast to our expectation of exaggerated cortical immune activation in schizophrenia, we found evidence of blunted expression of canonical NF- $\mathrm{kB}$ members where schizophrenia and neuroinflammation cooccurred (compared to inflammation in the cortex of people without schizophrenia). Although individuals classified as having high cortical inflammation in both diagnostic groups showed widespread increases in NF$\kappa B$-related mRNAs, almost all (8 of 9 mRNAs) of the differences between the two inflamed groups were found in canonical NF- $\kappa B$ transcripts (TLR4, IKK $\beta$, I $\kappa B \alpha, I \kappa B \beta$, $\mathrm{I} \kappa \mathrm{B} \varepsilon$, RelA, cRel, and NFKB1), which were decreased in high neuroinflammation schizophrenia compared to high neuroinflammation controls. TLR4 stimulation is a potent activator of microglia [32] and is implicated in both infectious and non-infectious (sterile) inflammation [33]. Furthermore, TLR4-mediated immune tolerance has been observed in microglia [34, 35], whereby chronic TLR4 stimulation results in reduced expression of TLR4 and microglial cytokine synthesis. Our finding of schizophrenia-specific relative suppression of TLR4 transcript plausibly reflects microglial quiescence in patients that is not seen in inflamed non-schizophrenic controls, and may reflect a more chronic neuroinflammatory environment in people with schizophrenia. Consistent with this hypothesis is the absence of clear cortical microglial activation in humans with schizophrenia in the postmortem brain $[8,36]$ and in living patients $[37,38]$. A recent transcriptome-wide study in the post-mortem cortex of people with schizophrenia found that the microglial transcriptional network is actually downregulated compared to controls, despite an overall upregulation of NF$\mathrm{kB}$-associated genes [8]. This is in line with our findings and suggests that NF- $\mathrm{B}$ may be suppressed in microglia but activated in other cells in the cortex of people with schizophrenia. However, mapping the changes in gene expression to specific brain cells capable of activating NF- $\mathrm{kB}$ and subsequent cytokine synthesis [39] will be necessary to confirm this possibility. The importance of canonical NF- $\mathrm{kB}$ signaling in cells of the myeloid lineage is highlighted by the impaired effector function of macrophages in the absence of cRel and NFKB1, two key subunits of this pathway [40]. In microglia, NFKB1/p50 is critical in shifting from the M1 pro-inflammatory phenotype into the M2 anti-inflammatory phenotype [41]. In this sense, canonical NF- $\mathrm{kB}$ in myeloid-derived cells is crucial for both effector function and the resolution of inflammation. While brain imaging studies 
have measured translocator protein (TSPO) in an attempt to assess microglial activation in schizophrenia, TSPO is not specific for microglia and cannot ascertain the role of microglia in the neuropathology of schizophrenia [42]. Interestingly, though deletion of nuclear NF- $\mathrm{BB}$ inhibitor HIVEP2 (Shn2) in mice leads to cortical immune activation [23, 24], we found significantly lower cortical mRNA for TLR4 in Shn2 KO mice compared to wild-type mice and concomitant lack of change in microglial activation marker Iba1 [23]. Further evidence of microglial suppression or lack of expected microglial activation in the context of HIVEP2 deficiency comes from our finding that the biggest NF- $\mathrm{kB}$ transcriptional change induced by Shn2 deletion was the downregulation of cortical NIK mRNA, which is highly enriched in microglia in mice [43] but not in human $[5,9]$. It may be that lower HIVEP2 mRNA, which we found only in people with schizophrenia who are inflamed in the cortex, is directly responsible for the lack of TLR4 mRNA increase in this group and underpins the interaction effect of inflammation and diagnosis on TLR4 mRNA we observed here. Together, these findings point to reduced capacity to both respond to and resolve inflammation in the cortex of people with schizophrenia.

In another glial population involved in neuroinflammation, the astrocytes, the non-canonical NF- $\mathrm{kB}$ subunit RelB is crucial for the coordination of adaptive immunity; its upregulation in "tolerant" astrocytes is necessary for suppression of inflammatory signaling upon subsequent stimulation [44]. While we found no difference in expression of any of the NF- $\mathrm{kB}$ subunits (potential dimerization partners) in Shn2 $\mathrm{KO}$ mice, we did see a trend toward RelB mRNA reduction, suggesting Shn2deficient astrocytes may be less able to appropriately suppress pro-inflammatory signaling. This may also be the case in people with schizophrenia, where we also found that RelB is decreased in the dorsolateral prefrontal cortex. An important limitation of our study that is inherent to homogenate-based assays is the inability to localize transcriptional changes to specific cell types. Indeed, in the absence of a foreign microbial antigen ("sterile" inflammation) as is the case in many cancers, in autoimmunity and possibly in schizophrenia, the neuroimmune environment is likely to reflect the efforts of several different cellular players searching for balance between inflammation and tolerance. The balance between these two states at any one time depends on many factors, including current stress levels, co-morbid physical conditions, chronicity of the inflammation, and frequency of flare-ups. Since some immune-related signaling molecules have beneficial effects in brain, such as maintaining and regulating synaptic function [45], a lower than normal level of cytokine inducers is not necessarily beneficial for normal human brain function. The comparatively weak NF- $k B$ induction reported here could represent a failure of a primary inflammatory response or could be a consequence of chronic cytokine activation, either of which could be interpreted as pathological or protective [39]. Despite this ambiguity, we do know that neurons have minimal basal or inducible NF$\kappa B$ [46], that reactive astrocytes are found in both Shn2 $\mathrm{KO}$ mice and high neuroinflammation schizophrenia $[23,24,47]$, and that NF- $\mathrm{kB}$ is essential in the adoption of a pro-inflammatory phenotype in astrocytes [48, 49]. Additionally, since microglial signals determine the functional and phenotypic fate of reactive astrocytes [50], suppression of microglia might contribute to an inappropriately prolonged pro-inflammatory response from astrocytes. We thus speculate that reactive astrocytes contribute largely to the NF- $\mathrm{kB}$ transcriptional signature-and to pro-inflammatory cytokine expression-in neuroinflammation-associated schizophrenia in the putative absence of microglial activation.

One transcriptional change in Shn2 KO cortex that was opposite to what we found in high neuroinflammation schizophrenia cortex was downregulation of CD40 mRNA. Though its ligand CD40L is found mostly on T cells $[51,52]$ and this ligand is not normally detected in brain $[5,43,52]$, CD40 upregulation is induced by proinflammatory cytokines in microglia and endothelial cells [53, 54]. As such, CD40 downregulation in Shn2 $\mathrm{KO}$ mice may represent another means by which to suppress microglial activation. Alternatively, since Shn2 KO mice have markedly less mature thymocytes than wild-type mice [55], we speculate that decreased endothelial expression of CD40 in Shn2 KO mice may also reflect a brain response to a reduction in circulating $\mathrm{T}$ cells. We found cortical upregulation of CD40 in patients with schizophrenia and elevated pro-inflammatory cytokine expression; however, this inflammation-associated increase was no different in non-schizophrenic controls, suggesting it is not a direct result of putative HIVEP2 deficiency (which was only seen in patients with neuroinflammation) in humans. Given other findings indicative of microglial suppression in schizophrenia, it is likely that cortical upregulation of the CD40 transcript in high neuroinflammation schizophrenia is driven by non-microglial cells that also express CD40 [5, 9].

While we found that exposure to anti-psychotic medication was positively correlated with expression of some NF- $\mathrm{kB}$ mRNAs, the magnitude of the correlations we report in this study is fairly low, and the effect of anti-psychotics on NF- $\mathrm{BB}$ activity in the brain may depend on the specific drug and inflammatory state. It has been reported that clozapine causes an increase in nuclear NF- $\kappa B$ activity in the mouse 
cortex [56], while haloperidol and olanzapine treatment do not appear to affect expression of NF- $\mathrm{B} B$ transcripts in monkey cortex [15]. Additionally, pretreatment with risperidone inhibits LPS-induced increases in RelA in mice [57]. We found a positive correlation between lifetime anti-psychotic exposure and mRNA for NF-kB-activating receptor TNFR, NF$\kappa B$ inhibitor $I \kappa B \alpha$, and NF- $\kappa B$ subunit precursor NFKB2 in the dorsolateral prefrontal cortex. ІкB $\alpha$ and (unprocessed) NFKB2 are anti-inflammatory, so their correlation with anti-psychotic exposure may indicate anti-inflammatory effects of these drugs. However, these transcripts are also induced by NF- $\mathrm{KB}$ activation $[58,59]$. Activation of the NF- $\kappa B$ pathway in murine glutamatergic neurons promotes dendritic spine and excitatory synapse formation [60,61]; thus, it is possible that anti-psychotics activate NF- $\mathrm{KB}$ in these cells in humans and that this contributes to their therapeutic effect in treating schizophrenia. Alternatively, since high levels of cortical inflammation are associated with more severe symptomatology and, consequently, a higher anti-psychotic dose, it is plausible that greater NF- $\mathrm{KB}$ activation (perhaps specifically through TNFR, which was also associated with antipsychotic exposure) leads to a requirement of more anti-psychotic treatment. Importantly, anti-psychotic agents can have both a direct anti-inflammatory effect and an indirect pro-inflammatory effect that is mediated by their association with weight gain and increased adiposity $[62,63]$, though the impact of BMI was not assessed in our study. Understanding how anti-psychotics may interact with the NF- $\mathrm{KB}$ pathway in both immune cells in the periphery and in brain cells are important aims for future studies.

\section{Conclusions}

In sum, our findings show an association between cortical non-canonical NF- $\mathrm{B}$ mRNA elevations and elevated neuroinflammatory status in a subset of people with schizophrenia that mainly appears to overlap with NF- $\mathrm{kB}$ mRNAs and elevated neuroinflammatory status in a subset of controls. Our results do find more specific diagnostic difference in transcriptional levels of canonical NF- $\mathrm{kB}$ pathway factors in those with high cortical inflammation suggesting they may utilize different cellular and intracellular means to achieve the same transcriptional ends (activation of cytokines). Further, our findings support that patients-but not nonschizophrenic controls-with cortical inflammation have decreased cortical HIVEP2 expression [14, 23], and that this may cause dysregulation of the NF- $\mathrm{kB}$ pathway in brain leading to putative blunting of normal inflammatory responses necessary to trigger various antiinflammatory mechanisms.

\section{Supplementary information}

Supplementary information accompanies this paper at https://doi.org/10. 1186/s12974-020-01890-6.

Additional file 1: Table S1. Detailed cohort demographics. Table S2. Relationship of NF-KB transcripts in dorsolateral PFC with demographic variables

\section{Abbreviations}

NF-kB: Nuclear factor kappa B; PFC: Prefrontal cortex; IL1R1: Interleukin-1 receptor type 1; TNFR1: Tumor necrosis factor receptor superfamily member 1A; TLR4: Toll-like receptor 4; CD40: Cluster of differentiation 40; LTBR: Lymphotoxin beta receptor; TNFR2: Tumor necrosis factor receptor superfamily member 1B; RelA: Proto-oncogene RelA; cRel: Proto-oncogene cRel; NFKB1: Nuclear factor kappa B subunit 1; NFKB2: Nuclear factor kappa B subunit 2; IKKa: Inhibitor of nuclear factor kappa B kinase subunit alpha; IKK : Inhibitor of nuclear factor kappa B kinase subunit beta; NIK: Nuclear factor kappa B-inducing kinase; IkBa: Nuclear factor kappa B inhibitor alpha; HIVEP2: Human immunodeficiency virus type 1 enhancer binding protein 2; mRNA: Messenger RNA; Shn2 KO: Schnurri-2 knockout; TRC: Tissue Resource Centre; SMRI: Stanley Medical Research Institute; SERPINA3: Serpin family A member 3; qPCR: Quantitative PCR

\section{Acknowledgements}

Schnurri-2 knockout mice were introduced from RIKEN Tsukuba Institute to Astellas via Fujita Health University; we thank Shunsuke Ishii and Tsuyoshi Miyakawa for the distribution of mice. In addition, we thank Amelia Brown for technical support in mice experiments.

\section{Authors' contributions}

MW, MM, AKW, and CSW contributed to the study design. CEM analyzed and interpreted human and mouse data, performed mouse experiments, and was the main contributor to writing the manuscript. MA prepared mouse tissue. AJL contributed to the data analysis. AJL, AKW, MW, MA, YK, MM, AKW, and CSW assisted in data interpretation and writing the manuscript. All authors read and approved the final manuscript.

\section{Funding}

CEM is supported by the Australian Government Research Training Program (RTP) scholarship (University of New South Wales) and Neuroscience Research Australia. AKW is supported by a National Breast Cancer Foundation Australia fellowship (PF-15-014), The Schizophrenia Research Institute and Neuroscience Research Australia (NeuRA). CSW is funded by the NSW Ministry of Health, Office of Health and Medical Research. CSW is a recipient of a National Health and Medical Research Council (Australia) Principal Research Fellowship (PRF) (\#1117079). Research reported in this publication was supported by the National Institute of Alcohol Abuse and Alcoholism of the National Institutes of Health under Award Number R28AA012725.

\section{Availability of data and materials}

The datasets generated and or analyzed during the current study are available in the SMRI repository, http://sncid.stanleyresearch.org.

\section{Ethics approval and consent to participate}

The present study was performed in accordance with the latest version of the Declaration of Helsinki after review by the Human Research Ethics Committee at the University of New South Wales (UNSW; HREC \#12435) and the latest version of the SMRI ethics (http://www.SMRIresearch.org/brainresearch/). Human tissues were received from the New South Wales Brain Tissue Resource Centre (TRC) at the University of Sydney (which is supported by the University of Sydney and The Schizophrenia Research Institute) and the Stanley Medical Research Institute (SMRI). TRC specimens were collected as part of the "Using our Brains" donor program established in 2002 as a premortem consent program. SMRI specimens were collected with informed consent from next-of-kin between September 1993 and June 2005. All animal experimental procedures were approved by the Institutional Animal Care and Use Committee of Astellas Pharma Inc. (Ibaraki, Japan), which has been awarded Accreditation Status by the Association of Assessment and Accreditation of Laboratory Animal Care (AAALAC) International. 


\section{Consent for publication}

Not applicable.

\section{Competing interests}

CSW is on an advisory board for Lundbeck, Australia Pty. The other authors declare that they have no competing interests.

\begin{abstract}
Author details
${ }^{1}$ Schizophrenia Research Laboratory, Neuroscience Research Australia, Barker Street, Randwick, Sydney, NSW 2031, Australia. ${ }^{2}$ School of Psychiatry, Faculty of Medicine, University of New South Wales, Sydney, NSW, Australia. ${ }^{3}$ Stanley Medical Research Institute, Kensington, Maryland, USA. ${ }^{4}$ Astellas Pharma Inc., Drug Discovery Research, Tsukuba, Japan. ${ }^{5}$ Drug Discovery Biology Theme, Monash University, Parkville, Australia. ${ }^{6}$ Department of Neuroscience \& Physiology, Upstate Medical University, Syracuse, New York, USA.
\end{abstract}

Received: 28 April 2020 Accepted: 6 July 2020

Published online: 17 July 2020

\section{References}

1. Liu T, Zhang L, Joo D, Sun SC. NF-KB signaling in inflammation. Signal Transduct Target Ther. 2017;2:e17023. https://doi.org/10.1038/sigtrans. 2017.23.

2. Kiss DL, Xu W, Gopalan S, Buzanowska K, Wilczynska KM, Rydel RE, et al. Duration of alpha 1-antichymotrypsin gene activation by interleukin-1 is determined by efficiency of inhibitor of nuclear factor kappa B alpha resynthesis in primary human astrocytes. J Neurochem. 2005;92(4):730-8. https://doi.org/10.1111/j.1471-4159.2004.02900.x.

3. Fillman SG, Cloonan N, Catts VS, Miller LC, Wong J, McCrossin T, Cairns M, Shannon Weickert C. Increased inflammatory markers identified in the dorsolateral prefrontal cortex of individuals with schizophrenia. Mol Psychiatry. 2013;18(2):206-14. https://doi.org/10.1038/mp.2012.110.

4. Fillman SG, Sinclair D, Fung SJ, Webster MJ, Shannon Weickert C. Markers of inflammation and stress distinguish subsets of individuals with schizophrenia and bipolar disorder. Transl Psychiatry. 2014;4(2):e365. https:// doi.org/10.1038/tp.2014.8.

5. Zhang Y, Catts VS, Sheedy D, McCrossin T, Kril JJ, Shannon Weickert C. Cortical grey matter volume reduction in people with schizophrenia is associated with neuro-inflammation. Transl Psychiatry. 2016a;6:e982. https:// doi.org/10.1038/tp.2016.238.

6. Purves-Tyson TD, Weber-Stadlbauer U, Richetto J, Rothmond DA, Labouesse MA, Polesel M, Robinson K, Shannon Weickert C, Meyer U. Increased levels of midbrain immune-related transcripts in schizophrenia and in murine offspring after maternal immune activation. Mol Psychiatry. 2019. https://doi. org/10.1038/s41380-019-0434-0

7. Lanz TA, Reinhart V, Sheehan MJ, Sukoff Rizzo SJ, Bove SE, James LC, Volfson D, Lewis DA, Kleiman RJ. Postmortem transcriptional profiling reveals widespread increase in inflammation in schizophrenia: a comparison of prefrontal cortex, striatum, and hippocampus among matched tetrads of controls with subjects diagnosed with schizophrenia, bipolar or major depressive disorder. Transl Psychiatry. 2019;9:151. https://doi.org/10.1038/ s41398-019-0492-8.

8. Gandal MJ, Zhang P, Hadjimichael E, Walker RL, Chen C, Liu S, et al. Transcriptome-wide isoform-level dysregulation in ASD, schizophrenia and, and bipolar disorder. Science. 2018;362(6420):eaat8127. https://doi.org/10. 1126/science.aat8127.

9. Zhang Y, Sloan SA, Clarke LE, Caneda C, Hayden-Gephart M, Grant GA, et al. Purification and Functional Characterization of Human Astrocytes. Neuron. 2016b;89(1):37-53. https://doi.org/10.1016/j.neuron.2015.11.013.

10. Meyer U, Schwarz MJ, Muller N. Inflammatory processes in schizophrenia: A promising neuroimmunological target for the treatment of negative/ cognitive symptoms and beyond. Pharmacol Ther. 2011;132(1):96-110. https://doi.org/10.1016/j.pharmthera.2011.06.003.

11. Fillman SG, Weickert TW, Lenroot RK, Catts SV, Bruggemann JM, Catts VS, Shannon Weickert C. Elevated peripheral cytokines characterize a subgroup of people with schizophrenia displaying poor verbal fluency and reduced Broca's area volume. Mol Psychiatry. 2016;21(8):1090-8. https://doi.org/10. 1038/mp.2015.90.

12. Jacomb I, Stanton C, Vasudevan $\mathrm{R}$, Powell $\mathrm{H}$, O'Donnell $M$, Lenroot $\mathrm{R}$, et al. C-Reactive Protein: Higher During Acute Psychotic Episodes and Related to
Cortical Thickness in Schizophrenia and Healthy Controls. Front Immunol. 2018;9:2230. https://doi.org/10.3389/fimmu.2018.02230.

13. Kirkpatrick B, Miller BJ. Inflammation and schizophrenia. Schizophr Bull. 2013, 39(6):1174-9. https://doi.org/10.1093/schbul/sbt141.

14. Volk DW, Chitrapu A, Edelson JR, Roman KM, Moroco AE, Lewis DA. Am J Psychiatr. 2015;172(11):1112-21. https://doi.org/10.1176/appi.ajp.2015. 15010019

15. Volk DW, Moroco AE, Roman KM, Edelson JR, Lewis DA. The role of the Nuclear Factor-KB Transcriptional Complex in Cortical Immune Activation in Schizophrenia. Biol Psychiatry. 2019;85(1):25-34. https://doi.org/10.1016/j. biopsych.2018.06.015.

16. Pahl HL. Activators and target genes of Rel/NF-kappaB transcription factors. Oncogene. 1999;18(49):6853-66. https://doi.org/10.1038/sj.onc.1203239.

17. Hoffman A, Natoli G, Ghosh G. Transcriptional regulation via the NF-kappaB signaling module. Oncogene. 2006;25(51):6706-16. https://doi.org/10.1038/ sj.onc.1209933.

18. Mussbacher M, Salzmann M, Brostjan C, Hoesel B, Schoergenhofer C, Dalter $\mathrm{H}$, et al. Cell Type-Specific Roles of NF-kB Linking Inflammation and Thrombosis. Front Immunol. 2019;10(85). https://doi.org/10.3389/fimmu. 2019.00085

19. Miller BJ, Buckley P, Seabolt W, Mellor A, Kirkpatrick B. Meta-Analysis of Cytokine Alterations in Schizophrenia: Clinical Status and Antipsychotic Effects. Biol Psychiatry. 2011;70(7):663-71. https://doi.org/10.1016/j.biopsych. 2011.04.013.

20. Kroken RA, Sommer IE, Steen VM, Dieset I, Johnsen E. Constructing the Immune Signature of Schizophrenia for Clinical Use and Research; An Integrative Review Translating Descriptives Into Diagnostics. Frontiers in Psychiatry. 2019;9(753). https://doi.org/10.3389/fpsyt.2018.00753.

21. Kumar A, Takada Y, Boriek AM, Aggarwal BB. Nuclear factor-kappaB: its role in health and disease. J Mol Med. 2004;82(7):434-48. https://doi.org/10. 1007/s00109-004-0555-y.

22. Kimura MY, Hosokawa $H$, Yamashita M, Hasegawa A, Iwamura C, Watarai $H$, et al. Regulation of T Helper Type 2 Cell Differentiation by Murine Schnurri2. J Exp Med. 2005;201(3):397-408. https://doi.org/10.1084/jem.20040733.

23. Murphy CE, Kondo Y, Walker AK, Rothmond DA, Matsumoto M, Shannon Weickert C. Mapping changes in brain expression of immune genes HIVEP2 and SERPINA3 in schizophrenia: regional and cellular divergence within the dorsolateral prefrontal cortex. in press. https:/doi.org/10.1016/j.bbi.2020.05.055.

24. Takao K, Kobayashi K, Hagihara H, Ohira K, Shoji H, Hattori S, et al. Deficiency of Schnurri-2, an MHC Enhancer Binding Protein, Induces Mild Chronic Inflammation in the Brain and Confers Molecular, Neuronal, and Behavioral Phenotypes Related to Schizophrenia.

Neuropsychopharmacology. 2013;38:1409-25. https://doi.org/10.1038/npp 2013.38.

25. Weickert CS, Sheedy D, Rothmond DA, Dedova I, Fung S, Garrick T, et al. Selection of Reference Gene Expression in a Schizophrenia Brain Cohort. Australian \& New Zealand Journal of Psychiatry. 2010;44(1):59-70. https:// doi.org/10.3109/00048670903393662.

26. Hagihara H, Catts VS, Katayama Y, Shoji H, Takagi T, Huang FL, et al. Decreased Brain pH as a Shared Endophenotype of Psychiatric Disorders. Neuropsychopharmacology. 2018;43(3):459-68. https://doi.org/10.1038/npp. 2017.167.

27. Oeckinghaus A, Ghosh S. The NF-kB Family of Transcription Factors and Its Regulation. Cold Spring Harb Perspect Biol. 2009;1(4):a000034. https://doi. org/10.1101/cshperspect.a000034.

28. Hayden MS, Ghosh S. NF-KB, the first quarter-century: remarkable progress and outstanding questions. Genes Dev. 2012;26:203-34. https://doi.org/10. 1101/gad.183434.111.

29. Karin M, Ben-Neriah Y. Phosphorylation Meets Ubiquination: The Control of NF-kB Activity. Annu Rev Immunol. 2000;18:621-63. https://doi.org/10.1146/ annurev.immunol.18.1.621.

30. Basak S, Kim H, Kearns JD, Tergaonkar V, O'Dea E, Werner SL, Benedict CA, Ware CF, Ghosh G, Verma IM, Hoffmann A. A fourth IkappaB protein within the NF-kappaB signaling module. Cell. 2007;128(2):369-81. https://doi.org/ 10.1016/j.cell.2006.12.033.

31. Romeo B, Brunet-Lecomte M, Martelli C, Benyamina A. Kinetics of Cytokine Levels during Antipsychotic Treatment in Schizophrenia: A Meta-Analysis. Int J Neuropsychopharmacol. 2018;21(9):828-36. https:/doi.org/10.1093/ijnp/pyy062

32. Kielian T. Toll-Like Receptors in Central Nervous System Glial Inflammation and Homeostasis. J Neurosci Res. 2006;83(5):711-30. https://doi.org/10.1002/ jnr.20767. 
33. Molteni M, Gemma S, Rossetti C. The Role of Toll-Like Receptor 4 in Infectious and Noninfectious Inflammation. Mediat Inflamm. 2016;2016: 6978936. https://doi.org/10.1155/2016/6978936.

34. Jack CS, Arbour N, Manusow J, Montgrain V, Blain M, McCrea E, et al. TLR Signaling Tailors Innate Immune Responses in Human Microglia and Astrocytes. J Immunol. 2005;175:4320-30. https://doi.org/10.4049/jimmunol. 175.7.4320.

35. Lajqi T, Lang G, Haas F, Williams DL, Hudalla H, Bauer M, et al. Memory-Like Inflammatory Responses of Microglia to Rising Doses of LPS: Key Role of PI3Ky. Front Immunol. 2019;10:2492. https://doi.org/10.3389/fimmu.2019. 02492.

36. Cai H, Catts VS, Webster MJ, Galletly C, Liu D, O'Donnell M, et al. Increased macrophages and changed brain endothelial cell gene expression in the frontal cortex of people with schizophrenia displaying inflammation. Mol Psychiatry. 2018. https://doi.org/10.1038/s41380-018-0235-x.

37. Di Biase MA, Zalesky A, O'Keefe G, Laskaris L, Baune BT, Weickert CS, et al. PET Imaging of Putative Microglial Activation in Individuals at Ultra-High Risk for Psychosis, Recently Diagnosed and Chronically III With Schizophrenia. Transl Psychiatry. 2017;7(8):e1225. https://doi.org/10.1038/tp. 2017.193.

38. De Picker LJ, Morrens M, Chance SA, Boche D. Microglia and Brain Plasticity in Acute Psychosis and Schizophrenia Illness Course: A Meta-Review. Frontiers in Psychiatry. 2017:8:238. https://doi.org/10.3389/fpsyt.2017.00238.

39. Becher B, Spath S, Goverman J. Cytokine networks in neuroinflammation. Nat Rev Immunol. 2017;17:49-59. https://doi.org/10.1038/nri.2016.123.

40. Courtine E, Cagnard N, Mazzolini J, Antona M, Pene F, Fitting C, et al. Combined Loss of cRel/p50 Subunits of NF-KB Leads to Impaired Innate Host Response in Sepsis. Innate Immunity. 2012;18(5):753-63. https://doi. org/10.1177/1753425912440296.

41. Taetzsch T, Levesque S, McGraw C, Brookins S, Luqa R, Bonini MG, et al. Redox Regulation of NF-kB p50 and M1 Polarization in Microglia. Glia. 2015; 63(3):423-40. https://doi.org/10.1002/glia.22762.

42. Notter T, Coughlin JM, Meyer U. Reconceptualization of translocator protein as a biomarker of neuroinflammation in psychiatry. Mol Psychiatry. 2018;23: 36-47. https://doi.org/10.1038/mp.2017.232.

43. Zhang Y, Chen K, Sloan SA, Bennett ML, Scholze AR, O'Keefe S, et al. An RNA-Seq transcriptome and splicing database of glia, neurons, and vascular cells of the cerebral cortex. J Neurosci. 2014;34(36):11929-47. https://doi. org/10.1523/JNEUROSCI.1860-14.2014.

44. Gupta AS, Waters MR, Biswas DD, Brown LN, Surace MJ, Floros C, et al. RelB Controls Adaptive Responses of Astrocytes During Sterile Inflammation. Glia. 2019;67(8):1449-61. https://doi.org/10.1002/glia.23619.

45. Boulanger LM. Immune Proteins in Brain Development and Synaptic Plasticity. Neuron. 2009;64(1):93-109. https://doi.org/10.1016/j.neuron.2009.09.001.

46. Listwak SJ, Rathore P, Herkenham M. Minimal NF-kB activity in neurons. Neuroscience. 2013;250:282-99. https://doi.org/10.1016/..neuroscience.2013.07.013.

47. Catts VS, Wong J, Fillman SG, Fung SJ, Shannon Weickert C. Increased expression of astrocyte markers in schizophrenia: Association with neuroinflammation. Australian \& New Zealand Journal of Psychiatry. 2014; 48(8):722-34. https://doi.org/10.1177/0004867414531078.

48. Kordula T, Bugno M, Rydel RE, Travis J. Mechanism of Interleukin-1- and Tumor Necrosis Factor a-Dependent Regulation of the a1-Antichymotrypsin Gene in Human Astrocytes (2000). J Neurosci. 2000;20(20):7510-6. https:// doi.org/10.1523/JNEUROSCI.20-20-07510.2000.

49. Choi SS, Lee HJ, Lim I, Satoh J, Kim SU. Human Astrocytes: Secretome Profiles of Cytokines and Chemokines. PLoS One. 2014;9(4):e92325. https:// doi.org/10.1371/journal.pone.0092325.

50. Jha MK, Jo M, Kim J, Suk K. Microglia-Astrocyte Crosstalk: An Intimate Molecular Conversation. Neuroscientist. 2018;25(3):227-40. https://doi.org/ $10.1177 / 1073858418783959$.

51. Su Al, Wiltshire T, Batalov S, Lapp H, Ching KA, Block D, et al. A gene atlas of mouse and human protein-encoding transcripts. Proc Natl Acad Sci U S A. 2004;101(16):6062-7. https://doi.org/10.1073/pnas.0400782101.

52. Uhlén M, Fagerberg L, Hallstrom BM, Lindskog C, Oksvold P, Mardinoglu A, et al. Tissue-based map of the human proteome. Science. 2015;347(6220): 394. https://doi.org/10.1126/science.1260419.

53. Benveniste EN, Nguyen VT, Wesemann DR. Molecular Regulation of CD40 Gene Expression in Macrophages and Microglia. Brain Behav Immun. 2004; 18(1):7-12. https://doi.org/10.1016/j.bbi.2003.09.001.
54. Omari KM, Dorovini-Zis K. CD40 expressed by human endothelial cells regulates CD4+ T cell adhesion to endothelium. J Neuroimmunol. 2003; 134(1-2):166-78. https://doi.org/10.1016/S0165-5728(02)00423-X

55. Takagi T, Harada J, Ishii S. Murine Schnurri-2 Is Required For Positive Selection of Thymocytes. Nat Immunol. 2001;2(11):1048-53. https://doi.org/ $10.1038 /$ ni728

56. Ibi D, de la Fuente RM, Kezunovic N, Muguruza C, Saunder JM, Gaitonde SA et al. Antipsychotic-induced Hdac2 transcription via NF-KB leads to synaptic and cognitive side effects. Nat Neurosci. 2017;20(9):1247-59. https://doi.org/ 10.1038/nn.4616.

57. MacDowell KS, Garcia-Bueno B, Madrigal JLM, Parellada M, Arango C, Mico $J A$, et al. Risperidone normalizes increased inflammatory parameters and restores anti-inflammatory pathways in a model of neuroinflammation. Int $J$ Neuropsychopharmacol. 2013;16:121-35. https://doi.org/10.1017/ S1461145711001775.

58. Sun SC, Ganchi PA, Ballard DW, Greene WC. NF-kappa B controls expression of inhibitor I kappa B alpha: evidence for an inducible autoregulatory pathway. Science. 1993;259(5103):1912-5. https://doi.org/10.1126/science. 8096091.

59. Lombardi L, Ciana P, Cappellini C, Trecca D, Guerrini L, Migliazza A, et al. Structural and functional characterization of the promoter regions of the NFKB2 gene. Nucleic Acids Res. 1995;23(12):2328-36. https://doi.org/10. 1093/nar/23.12.2328.

60. O'Mahony A, Raber J, Montano M, Foehr E, Han V, Lu SM, et al. NF-kappaB/ Rel regulates inhibitory and excitatory neuronal function and synaptic plasticity. Mol Cell Biol. 2006;26(19):7283-98. https://doi.org/10.1128/MCB. 00510-06.

61. Boersma MC, Dresselhaus EC, De Biase LM, Mihalas AB, Bergles DE, Meffert MK. A requirement for nuclear factor-kappaB in developmental and plasticity-associated synaptogenesis. J Neurosci. 2011;31(14):5414-25. https://doi.org/10.1523/JNEUROSCI.2456-10.2011.

62. Song X, Fan X, Li X, Zhang W, Gao J, Zhao J, et al. Changes in proinflammatory cytokines and body weight during 6-month risperidone treatment in drug naïve, first-episode schizophrenia. Psychopharmacology. 2013;231:319-25. https://doi.org/10.1007/s00213-013-3382-4.

63. Mondelli V, Howes O. Inflammation: its role in schizophrenia and the potential anti-inflammatory effects of antipsychotics. Psychopharmacology. 2014;231:317-8. https://doi.org/10.1007/s00213-013-3383-3.

\section{Publisher's Note}

Springer Nature remains neutral with regard to jurisdictional claims in published maps and institutional affiliations.
Ready to submit your research? Choose BMC and benefit from:

- fast, convenient online submission

- thorough peer review by experienced researchers in your field

- rapid publication on acceptance

- support for research data, including large and complex data types

- gold Open Access which fosters wider collaboration and increased citations

- maximum visibility for your research: over $100 \mathrm{M}$ website views per year

At $\mathrm{BMC}$, research is always in progress.

Learn more biomedcentral.com/submissions 